\title{
Getting to know the public
}

\author{
As research into the public perception of nanotechnology becomes more complex and rigorous, it is \\ increasingly clear that greater public awareness of nanotechnology will not, on its own, automatically \\ lead to widespread public acceptance.
}

It is well documented that most members of the public have not heard of nanotechnology ${ }^{1,2}$. This state of affairs could be construed as good news, because it means that nanotechnology continues to avoid the GMO-style backlash that many once considered inevitable. However, low levels of popular recognition in public opinion surveys could also be viewed as bad news because public funding is still very important for basic research in nanoscience and technology, even if companies now invest more in this field than governments ${ }^{3}$, and because the eventual success of the whole nanoenterprise will depend on people accepting and buying nano-enabled products.

There appeared to be some unalloyed good news in these same surveys because they reported that the small fraction of the public who were familiar with nanotechnology had a favourable view of it - a finding that led many to assume that the public in general would respond favourably to nanotechnology as they were told more about it. However, this 'deficit model' or 'familiarity hypothesis' has now been discredited in many areas of science and technology, including a 2007 survey that found some members of the public were more likely to turn antinano than pro-nano as their awareness of nanotechnology increased ${ }^{2}$. Three papers in this issue explore public perceptions of nanotechnology in more detail.

On page 87 Dan Kahan and colleagues report the results of a survey of 1862 adults that explored how cultural factors influence attitudes to nanotechnology. In particular, they investigated differences between people who are hierarchical individualists (that is, pro-commerce) and those who are egalitarian communitarians (anti-commerce). Kahan and co-workers divided their sample into two groups: the first group was provided with very little information (they were only told that nanotechnology involved very small particles), whereas those in the second group were given two paragraphs about the possible benefits and risks of nanotechnology. In the first group people who were moderately pro- and anti-commerce were equally likely (61\%) to see the benefits of nanotechnology as outweighing its risks. However, in the group that was exposed to information about the benefits and risks, $86 \%$ of respondents with pro-commerce views saw the benefits as being greater than the risks, whereas only $23 \%$ of those with anticommence views felt the same. Farewell, once more, to the familiarity hypothesis.

\section{Respondents in more religious countries were significantly less likely to see nanotechnology as morally acceptable.}

On page 91, meanwhile, Dietram Scheufele and colleagues describe a project that compared the influence of religious beliefs on attitudes towards nanotechnology in the United States and Europe (see also ref. 4). They found that respondents in more religious countries such as Austria, Ireland, Italy and the US were significantly less likely to see nanotechnology as morally acceptable or useful, compared with respondents in more secular countries such as Denmark, France, Germany and Sweden. They also found similar differences between religious and non-religious respondents within the US.

In a third paper, on page 95, Nick Pidgeon and co-workers used workshops, in the UK and the US, to compare attitudes towards nanotechnology for energy and health applications. Such workshops allow the researchers to study reactions to new technologies in more detail than is possible in public opinion surveys. In both countries, Pidgeon and co-workers found that workshop participants tended to focus on benefits rather than risks, and that energy applications were viewed in a substantially more positive light, compared with applications in health and human enhancement.

So what messages can we draw from these three papers? As Chris Toumey writes: "Together these studies alert us that reactions to nanotechnology will be shaped by a landscape of values, beliefs, concerns and other strong sentiments that were established in peoples' hearts long before most people heard or cared about nanometres, van der Waal's forces or carbon nanotubes." 5

Moreover, what should the nanotechnology community do? The answer, write Kahan and co-workers, lies in social psychology where "techniques for framing information on controversial policy issues in a manner that makes it possible for persons of diverse values to derive the same factual information from it" are being developed. On page 79 Steven Currall adds that it is important for social scientists "to translate their technical research findings into language that is directly useful to others".

Alert readers will notice that previous papers in Nature Nanotechnology based on public opinion surveys have been published in the Commentary section ${ }^{6,7}$, which is usually given over to subjects such as funding, policy, regulation and so on, whereas the three papers in this issue appear as letters alongside peer-reviewed research papers on nanocrystals, nanotubes and nanowires (ref. 8 provides links to all the papers we have published about public perceptions). This change of policy reflects the fact that these papers - like the papers on nanocrystals and so forth are based on rigorous scientific methods, and are refereed just as thoroughly. As Currall writes on page 79 , this also reflects the way that the "research literature on public perceptions of nanotechnology is maturing and becoming more rigorous, as increasingly complex and nuanced theoretical models of the factors that drive public sentiment about nanotechnology are subjected to empirical testing."

\footnotetext{
References

1. Nature Nanotech. 2, 731 (2007).

2. Peter D. Hart Research Associates <http://www.nanotechproject.org/ news/archive/poll_reveals_public_awareness_nanotech/> (2007).

3. Nature Nanotech. 4, 1 (2009).

4. Brossard, D., Scheufele, D. A., Kim, E. \& Lewenstein, B. V. Public Underst. Sci. doi:10.1177/0963662507087304 (2008).

5. Toumey, C. Nature Nanotech. doi:10.1038/nnano.2009.16 (2009).

6. Currall, S. C., King, E. B., Lane, N., Madera, J. \& Turner, S Nature Nanotech. 1, 153-155 (2006).

7. Scheufele, D. A. et al. Nature Nanotech. 2, 732-734 (2007)

8. <http://www.nature.com/nnano/focus/public_perceptions.html>
} 


\section{ERRATUM}

\section{Getting to know the public}

Nature Nanotechnology 4, 71 (2009); published online: 6 February 2009; corrected after print: 27 February 2009.

In the version of this editorial originally published, in the second sentence of the last paragraph the word 'referred' should have been 'refereed'. This has been corrected in the HTML and PDF versions. 